\title{
Diurnal moist convection in Majorca under sea breeze conditions: idealized numerical experiments
}

https://doi.org/10.31978/639-19-010-0.543

\author{
Javier Martín Martín ${ }^{1}$ (jmartinm@aemet.es) \\ Romualdo Romero March² (romu.romero@uib.es)
}

${ }^{1}$ AEMET / Delegación Territorial en la Comunidad Valenciana

${ }^{2}$ Universitat de les Illes Balears / Grup de Meteorologia

\begin{abstract}
Majorca has the adequate size to develop substantial sea breezes during the warm season, mainly along its long bays, that converge in the interior of the island. This low-level convergence acts as an effective triggering mechanism for thunderstorm development in situations of a convectively unstable air mass. The dependence of this triggering mechanism (intensity and location) on the large-scale flow and the possible role of the prominent orography of the island are two issues of scientific relevance and also of great practical interest for local forecasters.

With the aim of analyzing how the synoptic wind interacts with the sea breeze, thirty-two different atmospheric scenarios (plus the non-orographic counterparts) were simulated with the MM5 model at $1 \mathrm{~km}$ grid resolution. Results confirm a great sensitivity of the early afternoon breeze convergence and associated convection on the direction of the large-scale flow. The position and extent of the convective area are also strongly conditioned by the orography. The convection is basically modulated by the sea breeze characteristics for the cases with weak synoptic wind intensity, while it is largely activated by the orographic forcing for the cases with higher wind intensity.
\end{abstract}

KEY WORDS: sea breeze convergence; convection; orographic forcing; SAL scores.

\section{INTRODUCTION}

The sea breeze regime that affects the island of Majorca almost every day from May to September has been the subject of some analyses since the mid-twentieth century. The detail of these analyses and the diversity of approaches, including a few numerical simulations, have been increased in recent decades in parallel to technological development. The first investigation of the sea breeze regime was done by JANSÀ \& JAUME (1946). These authors resorted to climatological-empirical knowledge of the circulation from farmers and fishermen; a map with streamlines of the fully-developed sea breezes was plotted from the data collected, locating the main inflows along the Bays of Palma and Alcudia, and a secondary one along the south coasts (figure 1). The most important dynamical feature is the collision of the main airstreams in different sectors of the island interior, creating marked convergence lines, the most important extended along the northwest-southeast direction (figure 1). The authors also realized that there is a clear influence of the orography on the sea breeze streamlines. In particular, sea breezes are hardly visible along the northern coasts owing to the presence of the Serra de Tramuntana mountain range (with several peaks above $1000 \mathrm{~m}$ ) that extends parallel to that coast.

With this motivation in mind and in order to complement the ideas of previous works which have been carried out at the meteorology group of the Universitat de les Illes Balears, see bibliography. This study is a step further and pursues, first, to analyze numerically the interaction of the background synoptic flow with the sea 
a)

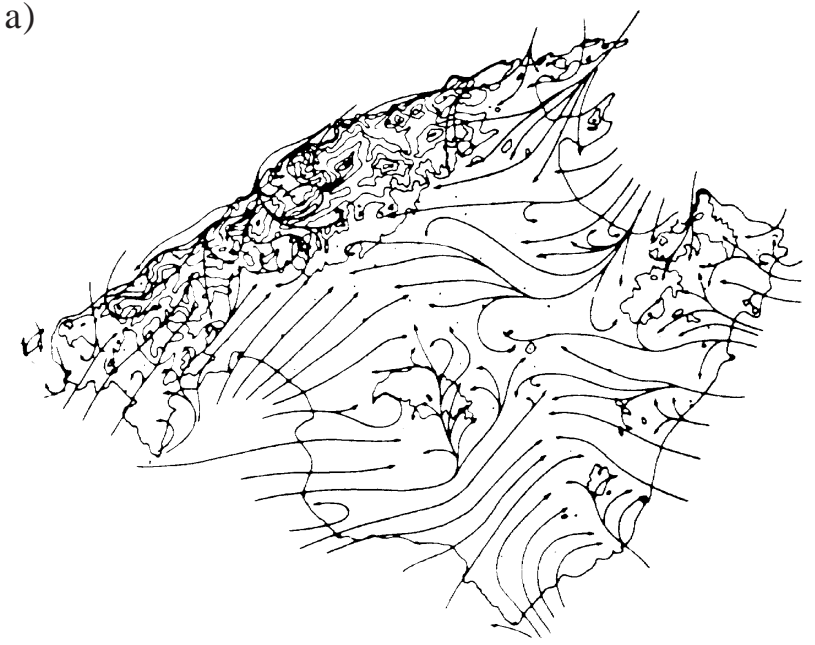

b)

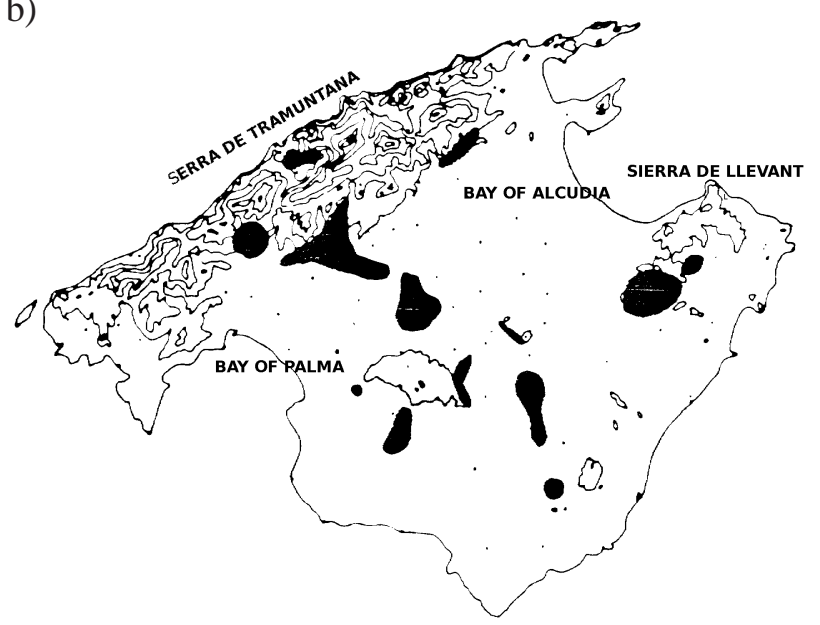

Figure 1. a) Streamlines of the mature sea breeze and b) outline of the main convergence areas over the island of Majorca, taken from the empirical analysis by JANSÀ \& JAUME (1946).

breeze generated in Majorca by the sea-land thermal contrasts during daytime, taking also into account the complex interplays with the local orography, and second, to establish the relevance of these interactions for the characteristics of the afternoon convection. For these reasons, the work is restricted to a convectively unstable environment and we will use the model accumulated precipitation field as the appropriate tracer to elaborate our conclusions.

\section{METHODOLOGY}

\subsection{Domain and simulation characteristics}

As we are dealing with idealized numerical simulations that depart from horizontally homogeneous atmospheric states which do not evolve except for the thermally driven circulations imposed by the island, a single domain with constant forcing at the lateral boundaries has been processed. It is centered at the geographical point $\left(39.6^{\circ} \mathrm{N}, 2.9^{\circ} \mathrm{E}\right)$, that is, exactly the center of the island of Majorca. The horizontal extent of the domain is $196 \times 196$ grid points with a resolution of $1 \mathrm{~km}$ under the Lambert Conformal map projection, an area wide enough to cover the whole island and a good portion of its maritime zones.

The initial and boundary conditions are provided on eleven standard pressure levels $(1000,950,900,800$, $750,650,600,550,450,350,100 \mathrm{hPa}$ ) and are vertically interpolated at the $31 \sigma$ levels that define the vertical mesh of the MM5 model. Vertical resolution is higher across the boundary layer depth (the lowest $\sigma$ layer is located $20 \mathrm{~m}$ above the ground approximately) in order to better resolve the turbulent processes and the crucial effects of land surface heating during daytime.

The simulation length is 24 hours, starting at 00 UTC to properly resolve the full diurnal cycle. In this respect, the used radiation parameters and sea surface temperature correspond to the climatological values of $30^{\text {th }}$ August.

\subsection{Definition of the initial and boundary conditions}

A series of idealized initial atmospheres with certain characteristics have been constructed in order to isolate as much as possible the changes that occur in response to the varying synoptic wind field. The vertical temperature and moisture profiles for all these idealized atmospheres have been initialized using the atmospheric sounding launched at the Aerodrome of Son Bonet on 30 ${ }^{\text {th }}$ August 2004 at 00 UTC. The thermodynamic vertical profile taken from that sounding, reveal enough instability for the development of moist convection in 
the simulations, as long as there is a proper triggering mechanism that can uplift the low-level parcels (figure 2). In addition, progressive warming and moistening of the surface air during the day would increase further the degree of instability.
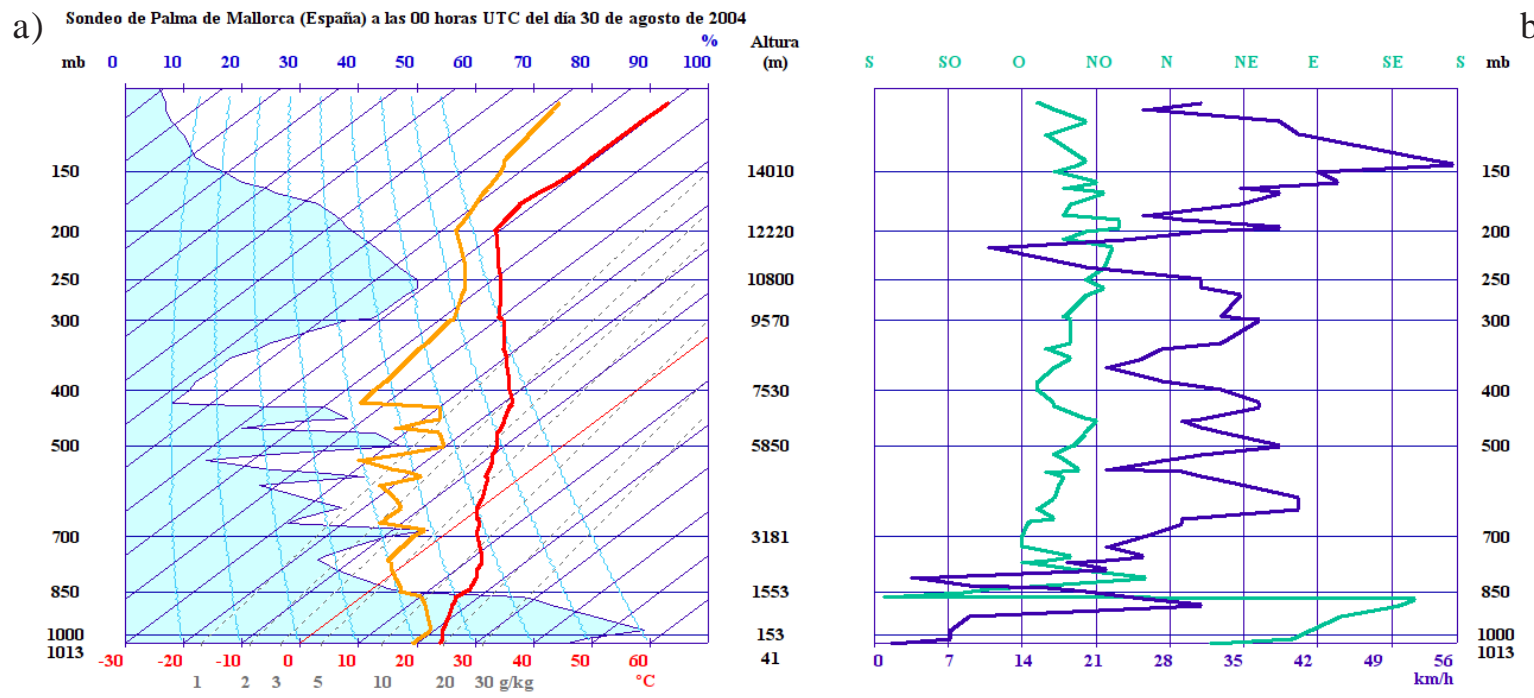

Figure 2. Plot of the atmospheric sounding launched at 00 UTC, $30^{\text {th }}$ August 2004, in Son Bonet (Majorca). a) The temperature and dew point vertical profiles are represented in a Skew-T thermodynamic diagram (relative humidity is also shown, blue curve according to the upper scale).

b) The module and direction of the wind are represented along the vertical.

Obtaining a simulation of reference, or control simulation, is the first step before the results of perturbed experiments can be correctly assessed. In the first instance, this control run was defined by setting to zero the initial and boundary values of the horizontal wind at low levels only, from surface to $700 \mathrm{hPa}$, and maintaining a westerly-northwesterly flow above. However, the modeled wind field over the island was found to be somewhat influenced by the exchange of momentum from the upper levels to the surface during the simulation, thus, the sea breeze could not be fully isolated from the synoptic wind field. Finally, we followed the same criteria of RAMIS \& ROMERO (1995) and our control simulation is initialized with an atmosphere at rest at all vertical levels (a condition maintained also for the boundary forcing) in order to fully isolate the sea breeze formation and evolution. This $1 \mathrm{~km}$ grid simulation takes into account the complex orography of Majorca, which influences the wind field generated by the thermal differences.

At the first part of this study, thirty-two scenarios with different wind profiles as initial and boundary conditions have been simulated. The aim is to assess how the dominant synoptic wind field affects the sea breeze convergence, under conditions of instability. Eight possible directions have been chosen (N, NE, E, SE, S, SW, W, NW) because the impact of the synoptic wind is hypothesized to be clearly different among these directions owing to the irregular shape of Majorca and the complexity of its orography (figure 1). Four possible wind intensities have been simulated for each direction: weak $(3.5 \mathrm{~m} / \mathrm{s})$, moderate $(7.0 \mathrm{~m} / \mathrm{s})$, moderate-strong $(10.5 \mathrm{~m} / \mathrm{s})$ and strong $(14.0 \mathrm{~m} / \mathrm{s})$, so, for instance, the simulations from the north will be labelled as (N-w, $\mathrm{N}-\mathrm{m}, \mathrm{N}-\mathrm{ms}$ and $\mathrm{N}-\mathrm{s}$ ). The zones of convergence of the sea breeze would be weakly affected for low wind intensities, but this convergence could be shifted downstream, if not entirely inhibited, for the cases with higher intensity. There are of course other triggering mechanisms, provided by the orography under impinging low-level currents, that can lead to convection.

The orography not only interacts with the synoptic wind field; it also exchanges momentum with the wind patterns generated by the sea-land thermal contrast. The mountains and associated valleys play an important role in the evolution of the sea breeze (e.g. RAMIS \& ROMERO (1995)); the contribution of these topographic 
features could even lead to early sea breeze development, due to its connection with the intrinsic mountainsvalleys thermal circulations. The complex orography of Majorca tends to determine the distribution of surface heating over the island interior and the locations free of significant blocking into which the sea breeze front can penetrate. These conditions make that the main sea breezes fronts in Majorca take place in certain areas such as the Bay of Palma or the Bay of Alcudia (recall figure 1).

Given the crucial role of the orographic factor, in the second part of this project the above idealized scenarios have been run again, but this time with the orography of the whole island of Majorca set to zero meters above sea level. As the relief is not taken into account in these non-orographic experiments, sea breeze fronts should develop along all the shores, producing strong convergences within the island, where a greater amount of precipitation would be expected.

\section{RESULTS}

\subsection{Control Simulation}

The wind field depends exclusively on the differential heating between different land uses and the sea, due to the synoptic wind field having been annulled in the whole vertical. The mature sea breeze has been plotted in figure 3. There are two main inflows well defined along the Bay of Palma and the Bay of Alcudia, and a secondary inflow located in the southeast. The accumulative convective precipitation is a result of these three ingredients: the constant supply of moisture provided by the sea breeze, certain instability provided by the atmospheric sounding, and the enough intensity of the sea breeze in order to converge in the center of Majorca. The convergence of sea breezes supplies enough energy in order to raise a parcel of air up reaching the Level of Free Convection (LFC), and releasing the CAPE available at this moment. Figure 3 shows that the precipitation distribution is influenced by the orography.

The precipitation field will be taken as a reference in order to apply the verification technique object-oriented SAL.

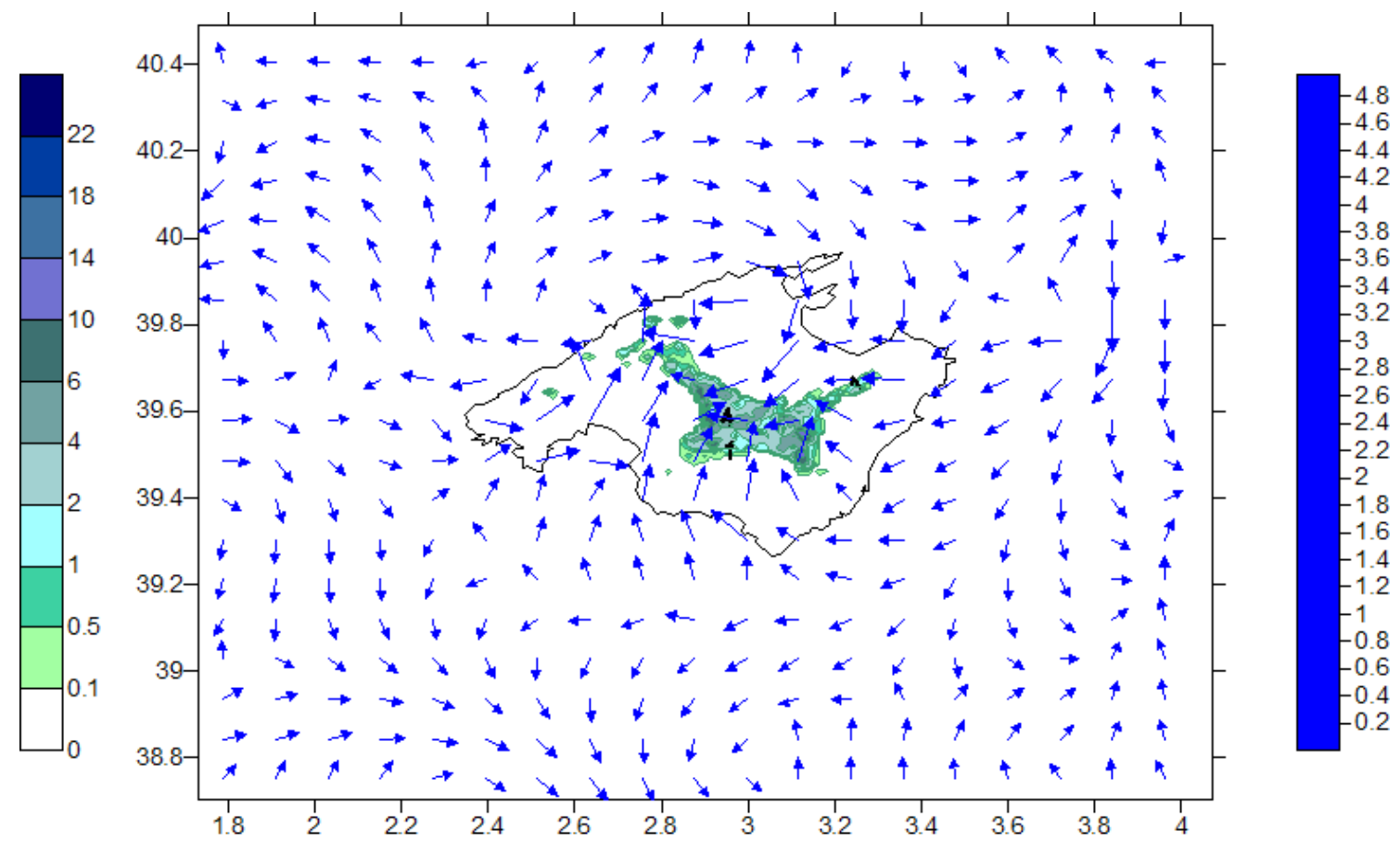

Figure 3. Control Simulation, the accumulated precipitation field with the wind field at 14 UTC. 


\subsection{Simulation with orography}

The comparisons between each simulation with respects to the control simulation have been plot in order to analyze and verify the differences between them. The comparisons of each scenario with the control simulation allow us to observe visually, and quantify the differences in the accumulated precipitation field, using the verification techniques object-oriented SAL. The component location $(\mathrm{L})$, quantifies the displacement suffered by convective processes, due to the displacement of the center of mass calculated for each simulation in respect to the reference field is implied in $(\mathrm{L})$. The component Amplitude (A), takes into account the variation of the total precipitation in respect to the control simulation. For each direction, the variation of the precipitation as the wind intensity conditions are increasing, can be quantified attending to the evolution of (A). The component Structure (S) is more complex, but in the case that (A) keeps constant, a negative variation of (S) gives the idea on the one hand that, the precipitation simulated is more peaked or convective respect the control simulation. On the other hand, a positive variation of (S) means that it is more homogeneous or stratiform in respect to the control simulation.

There is a threshold from which the synoptic wind is strong enough in order to displace the convergence out of the island and thus, there is not convective precipitation from this origin as a trigger mechanism. From now on, the convective processes observed will be by orographic forcing, due to the unstable conditions provided by the atmospheric sounding.

For the northwest winds: as the initial and boundary conditions increase in intensity, the convective core decreases in the amount of precipitation, it is given by the gradual decrease in the score (A); except for the case of NW-m, where there is a relative increase of precipitation, which could be due to the presence of Randa, with a height of $531 \mathrm{~m}$. The positive evolution of the score (L) shows that the displacement of the convergence area towards south-west increases as the wind intensity increase. The score (S) evolves in the same way as (A), marking a convective character for all the scenarios. The convection obtained for NW-ms and NW-s is located outside the island.

The east wind does not find much resistance throughout the Bay of Alcudia, leading to convection under sea breeze conditions is rapidly annulled. It is only the case of E-w, where the sea breeze developed in the Bay of Palma is strong enough in order to converge within the island. The amount of precipitation decrease and the main convective cell is displaced westwards. For E-s, the convective cells are confined in the mountainous area of the Serra de Tramuntana for higher wind speed intensities, being that the orographic forcing relevant. The Serra de Tramuntana relief is oriented around $45^{\circ}$ to the incident wind; therefore, the perpendicular component of the wind to the mountain range does not acquire high values.

The convection under sea breeze conditions is inhibited for a low threshold of synoptic wind speed, due to the fact that there is a secondary entrance of the wind located in the southwest of Majorca. For SE-w, the convergence of the sea breezes prevails as a trigger mechanism with a total amount of precipitation three times lower than the control simulation, attending to the score value of $A=-1$. As the wind increases in intensity, the orographic forcing becomes stronger due to the incident wind is perpendicular to the Serra de Tramuntana, which is more efficient for the development of convection. For SE-s, the total amount of precipitation is almost the same as the control simulation. In this case, the scores $(\mathrm{S})$ shows the precipitation is less peaked than the control simulation. It is interesting to note that the convective area extends outside the Serra de Tramuntana, it could be that the gust front generated by the leading edge of cold air rushing down and out from the convective cells.

The south wind does not find a direct inflow into the island, but the topography located in the south of Majorca does not offer a significant resistance. Therefore, there is only one clear evidence of convection under sea breeze conditions for the case of S-w. The convective areas increase along the Serra de Tramuntana as the wind intensity increase due to the orographic forcing, which it is implied within the score $(\mathrm{L})$ due to the contribution of $\left(\mathrm{L}_{2}\right)$, see WERNLI et al. (2008). The precipitation is increasing with the wind speed when the trigger mechanism is the orographic forcing, the reader is referred to see the evolution of the score (A). 
The southwest synoptic wind find one of the main inflows through the Bay of Palma, giving an extra component to the sea breeze that has been generated. On the contrary, the sea breeze formatted in the Bay of Alcudia is only strong enough to keep the area of convergence within the island, for SW-w. For SW-m, in addition to the persistence of the sea breeze convergence, a convective cell is also observed in Serra de Llevant, where the trigger mechanism is the orographic forcing. This combination of both trigger mechanisms lead to the total of precipitation is increased significantly compared with the scenario SW-w. The scenarios with higher wind intensity, the orographic is not relevant at all, due to the incident wind is parallel to the Serra de Tramuntana. The precipitation is almost confined in the Serra de Llevant and Cap de Formentor.

\begin{tabular}{|c|c|c|c|c|c|c|c|c|}
\hline $\mathrm{ff}(\mathrm{m} / \mathrm{s})$ & S & $\Delta S$ & A & $\Delta \mathrm{A}$ & L & $\Delta \mathrm{L}$ & L1 & $\mathrm{L} 2$ \\
\hline NE-W & -0.48 & & -0.56 & & 0.0064 & & 0.0058 & 0.0006 \\
\hline NE-m & -0.04 & 0.44 & -0.39 & 0.17 & 0.0013 & -0.0051 & 0.0001 & 0.0012 \\
\hline NE-ms & -1.42 & -1.62 & -1.57 & -1.18 & 0.0999 & 0.1000 & 0.0979 & 0.0019 \\
\hline NE-S & -1.66 & -0.24 & -1.61 & -0.04 & 0.1402 & 0.0403 & 0.1374 & 0.0028 \\
\hline$E-w$ & -0.75 & & -0.67 & & 0.0058 & & 0.0055 & 0.0008 \\
\hline$E-m$ & -1.76 & -1.01 & -1.30 & -0.63 & 0.0914 & 0.0856 & 0.0891 & 0.0023 \\
\hline E-ms & -1.84 & -1.62 & -1.86 & -0.56 & 0.1495 & 0.1000 & 0.1469 & 0.0026 \\
\hline E-s & -1.32 & 0.52 & -1.25 & 0.61 & 0.1135 & -0.0400 & 0.1107 & 0.0028 \\
\hline SE-W & -0.90 & & -1.00 & & 0.0082 & & 0.0075 & 0.0008 \\
\hline SE-m & -1.90 & -1.00 & -1.84 & -0.84 & 0.0769 & 0.0687 & 0.0753 & 0.0016 \\
\hline SE-ms & -1.13 & 0.77 & -1.28 & 0.56 & 0.0092 & 0.1000 & 0.0069 & 0.0023 \\
\hline SE-S & -0.91 & 0.22 & 0.11 & 1.39 & 0.1678 & 0.1586 & 0.1658 & 0.0021 \\
\hline S-w & -0.73 & & -0.92 & & 0.0552 & & 0.0546 & 0.0007 \\
\hline S-m & -1.22 & -0.49 & -1.39 & -0.47 & 0.0259 & -0.0293 & 0.0244 & 0.0015 \\
\hline S-ms & -1.84 & -0.62 & -1.86 & -0.47 & 0.1768 & 0.1000 & 0.1754 & 0.0014 \\
\hline S-S & -1.13 & 0.71 & -0.26 & 1.60 & 0.2410 & 0.0642 & 0.2395 & 0.0015 \\
\hline SW-W & -0.75 & & -1.26 & & 0.1216 & & 0.1210 & 0.0006 \\
\hline sW-m & -1.03 & -0.28 & -0.30 & 0.96 & 0.1090 & -0.0126 & 0.1078 & 0.0011 \\
\hline sW-ms & -1.35 & -0.32 & -0.91 & -0.61 & 0.1589 & 0.1000 & 0.1571 & 0.0017 \\
\hline SW-s & -1.19 & 0.16 & -1.10 & -0.19 & 0.1516 & -0.0073 & 0.1497 & 0.0019 \\
\hline W-w & -0.88 & & -0.58 & & 0.0873 & & 0.0870 & 0.0003 \\
\hline W-m & -0.03 & 0.85 & -0.26 & 0.32 & 0.0112 & -0.0761 & 0.0101 & 0.0011 \\
\hline W-ms & -0.87 & -0.84 & -1.12 & -0.86 & 0.0189 & 0.1000 & 0.0172 & 0.0017 \\
\hline W-s & -1.61 & -0.74 & -1.64 & -0.52 & 0.3137 & 0.2948 & 0.3129 & 0.0008 \\
\hline NW-W & -0.63 & & -0.65 & & 0.0037 & & 0.0335 & 0.0002 \\
\hline NW-m & -0.48 & 0.15 & -0.65 & 0.00 & 0.0196 & 0.0159 & 0.0189 & 0.0007 \\
\hline NW-ms & -0.82 & -0.34 & -1.17 & -0.52 & 0.0199 & 0.1000 & 0.0186 & 0.0013 \\
\hline NW-s & -1.20 & -0.38 & -0.35 & 0.82 & 0.2685 & 0.2486 & 0.2676 & 0.0009 \\
\hline $\mathrm{N}-\mathrm{w}$ & -1.28 & & -1.03 & & 0.1559 & & 0.1553 & 0.0005 \\
\hline $\mathrm{N}-\mathrm{m}$ & -0.60 & 0.68 & -0.97 & 0.06 & 0.0042 & -0.1517 & 0.0031 & 0.0011 \\
\hline $\mathrm{N}-\mathrm{ms}$ & -1.90 & -1.30 & -1.97 & -1.00 & 0.0261 & 0.1000 & 0.0244 & 0.0016 \\
\hline$N-s$ & -1.56 & 0.34 & -1.15 & 0.82 & 0.0190 & -0.0071 & 0.0175 & 0.0015 \\
\hline
\end{tabular}

Table 1. Evolution of the scores Structure (S), Amplitude (A) and Location (L) for the initial and boundary of all wind directions. 
The convergence of the sea breezes persist for all the wind speeds, due to the west wind at the low troposphere is braked by Serra de Tramuntana, and the secondary inflow of the sea breeze located at the southeast of Majorca is strong enough to keep the convective area inland. The total amount of precipitation gradually decreases as the wind conditions increase, due to the fact that the orographic forcing is not relevant to the convection. The incident wind has an angle of approximately $45^{\circ}$ in respect to the Serra de Tramuntana.

For NW-w, the northwest wind at 14 UTC incident perpendicularly to the Serra de Tramuntana, being not able to surrounds the mountain range. As the wind speed increases, downdraft acceleration is observed leeward. These balances among the instability in the area, the perpendicular component of the incident wind and the height of the mountain range is related to the Froude number. Although the Serra de Tramuntana offers a lot of resistance to the northwest winds, the convergence under sea breeze conditions is not observed for all scenarios. The downdraft acceleration leeward is stronger than the sea breeze generated in the south of the island. For NW-s, the convection under orographic forcing lead to a convective precipitation in the main reliefs of Majorca.

The north wind is a common scenario which it is known as Tramuntana, it occurs when there are low pressures in the north of Italy and high pressures in the southwest of France. Generally, the wind strikes east of Majorca. The convergence under sea breeze conditions is observed for $\mathrm{N}-\mathrm{w}$ and $\mathrm{N}-\mathrm{m}$, where the total amount of precipitation is almost three times lower than the control simulation. The convection under orographic forcing starts for N-s, over the Serra de Tramuntana.

\subsection{SAL Diagram}

To summarize, in figure 4, a SAL diagram has been plotted in order to summarize the thirty-two simulations with orography. If the score (A) is attended, the amount of precipitation of the simulations is less than the control simulation, except for the case with the south-east wind with an intensity of $14.0 \mathrm{~m} / \mathrm{s}$, where the orographic forcing was relevant. There is a relation between (A) and (S) due to the fact that most of the points are located close to the straight line which makes an angle of $45^{\circ}$ with the negative direction of (S) axis. This is due to the fact that all the character precipitations events are convective. If the trigger mechanism was only the convergence of the sea breezes, it is expected that the convective cells decrease in size and goes away from the center of the island, or even that they vanish. Therefore, a larger

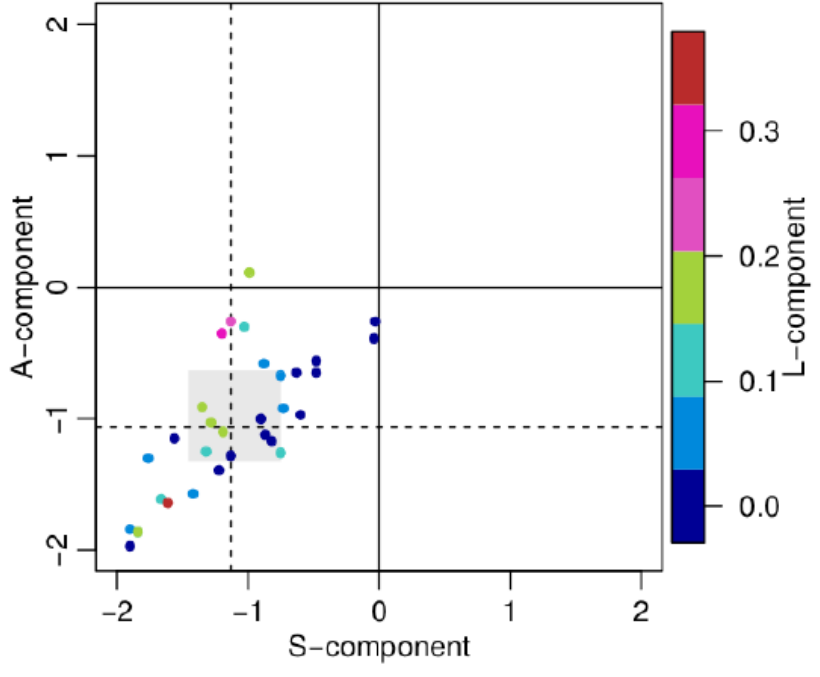

Figure 4. SAL Diagram of the thirty-two different scenarios with orography. value of $(\mathrm{L})$ is expected when the value of $(\mathrm{A})$ decreases, but it is not observed in figure 4 due to the influence of the orography as a trigger mechanism.

This project has been extended in order to confirm all the conclusions that have been analyzed so far. The thirty-two simulations have been running again with the orographic set to zero.

\subsection{Simulations without orography}

The thirty two simulations have been classified according to the trigger mechanism of the convection in two groups: the first group includes sixteen simulations with an initial and boundary wind intensities of $3.5 \mathrm{~m} / \mathrm{s}$ and $7.0 \mathrm{~m} / \mathrm{s}$, where the convergence under sea breeze conditions dominates over the orographic forcing as a trigger mechanism. The opposite happens in the second group which includes the remaining sixteen simulations with an initial and boundary wind intensities of $10.5 \mathrm{~m} / \mathrm{s}$ and $14.0 \mathrm{~m} / \mathrm{s}$. 
The score Amplitude (A) has been analyzed in order to study the trend of total amount of precipitation in both groups:

\begin{tabular}{|c|c|c|c|c|}
\hline AMPLITUDE & \multicolumn{2}{|c|}{$\mathbf{1}^{\text {st }}$ group } & \multicolumn{2}{c|}{$\mathbf{2}^{\text {nd }}$ group } \\
\hline $\mathbf{f f} / \mathbf{d d}$ & $\mathbf{3 . 5} \mathbf{~ m} / \mathbf{s}$ & $\mathbf{7 . 0} \mathbf{~} / \mathbf{s}$ & $\mathbf{f f} / \mathbf{d d}$ & $\mathbf{3 . 5} \mathbf{~} / \mathbf{s}$ \\
\hline $45^{\circ}$ & 0.72 & 0.13 & 0.30 & -0.80 \\
\hline $90^{\circ}$ & 0.78 & 0.87 & -0.94 & -2.00 \\
\hline $135^{\circ}$ & 0.84 & 1.76 & -1.69 & -2.00 \\
\hline $180^{\circ}$ & 0.79 & 1.19 & -1.23 & -2.00 \\
\hline $225^{\circ}$ & 1.36 & 0.20 & -0.32 & -1.32 \\
\hline $270^{\circ}$ & 0.63 & 0.29 & -1.92 & -2.00 \\
\hline $315^{\circ}$ & 0.14 & -0.07 & -1.78 & -2.00 \\
\hline $360^{\circ}$ & 0.83 & 0.24 & -0.79 & -2.00 \\
\hline
\end{tabular}

Table 2. Evolution of the scores Amplitude (A) for each simulation with the orography establish in one meter above the sea level, taking as a reference its counterpart with orography.

The total amount of precipitation increases in the scenarios of the $1^{\text {st }}$ group except for the case of the scenario with initial and boundary wind conditions with a direction of $315^{\circ}$ and intensity of $7.0 \mathrm{~m} / \mathrm{s}$, positives values of (A). The sea breezes can penetrate into the island along all its shores, intensifying the convergence area and bringing more moisture, causing a larger and more intensive convective precipitation area.

On the contrary, the total amount of precipitation decreases in the scenarios of the $2^{\text {nd }}$ group except for the one with an initial and boundary wind conditions with a direction of $45^{\circ}$ and intensity of $10.5 \mathrm{~m} / \mathrm{s}$, see negatives values of (A). It is due in fact that with the orographic established at zero meter above sea level, there is not orographic forcing. Thus, there is residual convective precipitation caused by the deceleration of the synoptic wind field due to the differential diurnal heating.

\section{CONCLUSIONS}

It has been detected that there is a threshold from which orographic forcing dominates the development of convection, to the detriment of the convergence of sea breeze. The complex orography of Majorca determines the wind inflow, limiting the intensity and the moisture supply of the convergence at low levels. For the eight possible scenarios simulated, with low initial and boundary wind speed conditions of $3.5 \mathrm{~m} / \mathrm{s}$, the convergence of sea breeze undergoes a slight shift but still remains within the island. It is for the scenarios with $7.0 \mathrm{~m} / \mathrm{s}$, when the convergence is only keeping inland, for the directions where the wind at low levels experiences a slowdown when it interacts with the relief, it happens at the north, northeast, west and southwest winds. On the contrary, for the initial and boundary wind speed conditions of $10.5 \mathrm{~m} / \mathrm{s}$ and $14.0 \mathrm{~m} / \mathrm{s}$, most of the convective precipitation obtained as a result of the orographic forcing, which efficiency depends on the angle between the incident wind and the main mountain ranges of the island, being a reason why the southeast and northwest winds, with an initial and boundary wind speed of $14.0 \mathrm{~m} / \mathrm{s}$ shows higher values of precipitation, which is quantified by the amplitude score. The wind incident is almost perpendicular to the Serra de Tramuntana mountain range. It is also relevant for the northwest wind the second main relief of Majorca, the Serra de Llevant. The south wind shows high values of precipitation, although the incident wind is not perpendicular to the main mountain range, but the convection is still very effective in the area of the Serra de Tramuntana located further south. This is due to the incident winds impinging directly from the sea.

The results of the thirty-two simulations obtained with the orography set in one meter above sea level, for the same initial and boundary conditions supports that; it is obtained under certain instability conditions, when the 
trigger mechanism predominant is the convergence of the sea breeze, the accumulative convective precipitation increases notably. This is due to the fact that the sea breeze can form on all the shores of the island, which increases the moisture supply and the intensity of the convergence at low levels. On the contrary, less accumulated convective precipitation is obtained when the trigger mechanism predominant is the orographic forcing, not having precipitation when there is not any slowdown of the wind, and the only trigger mechanism is the orographic forcing.

Another interesting line of work could be to study the influence of the mountain breeze generated by differential heating on the slopes of the major mountain ranges of the island, mainly the Serra de Tramuntana. Perhaps a higher resolution domain is needed in order to detect the component of the wind at low levels, which could be affected during the diurnal heating.

\section{ACKNOWLEDGMENTS}

A los compañeros de AEMET y del Grupo de Meteorología de la UIB, grandes profesionales y personas.

\section{REFERENCES}

GARC, A., 1998. Caracterización de la brisa en Santander, 1946, 9-13.

GonzÁlez, J., Guijarro, J. A. and Jansé, A., 1998. Caracterización de la brisa en Mallorca. IX Asamblea Nacional de Geodesia y Geofísica (Almería 9-13/Feb): 347-.

JANSÀ, J. M. and Jaume, E., 1946. The sea-breeze regime in Mallorca island (in Spanish). Rev. de Geofísica, 19, 304-328.

RAmIs, C. and Alonso, S., 1988. Sea breeze convergence line in Majorca: A satellite observation, Weather, 43, pp. 288-293.

Ramis, C., Jansì, A. and Alonso, S., 1990. Sea breeze in Majorca. A numerical study. Meteorology and Atmospheric Physics, 42, pp. 249-258.

Regional Severe Storm Environment. Part I: Three-Dimensional Simulaltions. Monthly Weather Review.

RAMIS, C. and JANSÀ, A., 1989. Simulación numérica de la brisa en Mallorca.

RAmis, C. and Romero, R., 1995. A First Numerical Simulation of the Developmend and Structure of the Sea Breeze in the Island of Mallorca. Annales Geophysicae, 13, 981-994.

Romero, R. and Ramis, C., 1996. Anumerical study of the transport and diffusion of coastal pollutants during the breeze cycle in the Island of Mallorca. Annales Geophysicae, 14 (3), 351-363.

Saito, K., KeEnan, T., Holland, G. and Puri, K., 2001. Numerical Simulation of the Diurnal Evolution of Tropical Island Convection over the Maritime Continent. Monthly Weather Review, 129 (3), 378-400.

Wernli, H., Hoffman, C. and Zimmer, M., 2009. Spatial Forecast Verification Methods Intercomparison Project: Application of the SAL Technique. Weather and Forecasting, 24, 1472-1484.

Wernli, H., Paulat, M., Hagen, M. and Frei, C., 2008. SAL — A Novel Quality Measure for the Verification of Quantitative Precipitation Forecast. Monthly Weather Review, 136, 4470-4487. 
